\title{
AN ITERATIVE ALGORITHM ON FIXED POINTS OF RELAXED LIPSCHITZ OPERATORS
}

\author{
RAM U. VERMA \\ International Publications, 12046 Coed Drive \\ Orlando, Florida 32826 USA \\ and \\ Istituto per la Ricerca di Base \\ I-86075 Monteroduni (IS), Molise, Italy
}

(Received February, 1996; Revised November, 1996)

Fixed points of Lipschitzian relaxed Lipschitz operators based on a generalized iterative algorithm are approximated.

Key words: Iterative Algorithm, Fixed Point, Relaxed Lipschitz Operator.

AMS subject classifications: $47 \mathrm{H} 10$.

\section{Introduction}

Recently, Wittman [6, Theorem 2], using an iterative procedure

$$
x_{n}=\left(1-a_{n}\right) x_{0}+a_{n} T x_{n-1} \text { for } n \geq 1,
$$

approximated fixed points of nonexpansive mappings $T: K \rightarrow K$ from a nonempty closed convex subset $K$ of a real Hilbert space $H$ into itself, where $x_{0}$ is an element of $K$ and $\left\{a_{n}\right\}$ is an increasing sequence in $[0,1)$ such that

$$
\lim _{n \rightarrow \infty} a_{n}=1 \text { and } \sum_{n=1}^{\infty}\left(1-a_{n}\right)=\infty
$$

This result refines a number of results including [1].

Here our aim is to approximate the fixed points of Lipschitzian relaxed Lipschitz operators in a Hilbert space setting. As such, the iterative algorithm (1) is not suitable for our purpose, so we apply a modified iterative algorithm which reduces to (1).

Let $H$ be a Hilbert space and $\langle u, v\rangle$ and $\|u\|$ denote, respectively, the inner product and norm on $H$ for $u, v$ in $H$.

An operator $T: H \rightarrow H$ is said to be relaxed Lipschitz if, for all $u, v$ in $H$, there exists a constant $r>0$ such that

$$
\langle T u-T v, u-v\rangle \leq-r\|u-v\|^{2} .
$$


The operator $T$ is called Lipschitz continuous (or Lipschitzian) if there exists a constant $s>0$ such that

$$
\|T u-T v\| \leq s\|u-v\| \text { for all } u, v \text { in } H .
$$

Next, we consider the main result on the approximation of the fixed points of Lipschitzian relaxed Lipschitz operators using a modified iterative algorithm which contains a number of iterative schemes including those considered by the author $[4,5]$ as special cases.

\section{The Main Result}

Theorem 1: Let $H$ be a real Hilbert space and $K$ be a nonempty closed convex subset of $H$. Let $T: K \rightarrow K$ be a relaxed Lipschitz and Lipschitz continuous operator on $K$. Let $r \geq 0$ and $s \geq 1$ be constants for relaxed Lipschitzity and Lipschitz continuity of $T$, respectively. Let $F=\{x$ in $K: T x=x\}$ be nonempty, and let $\left\{a_{n}\right\}$ be a sequence in $[0,1]$ such that

$$
\sum_{n=0}^{\infty} a_{n}=\infty \text { for all } n \geq 0 .
$$

Then for any $x_{0}$ in $K$ the sequence $\left\{x_{n}\right\}$ defined by

$$
x_{n+1}=\left(1-a_{n}\right) x_{n}+a_{n}\left[(1-t) x_{n}+t T x_{n}\right] \text { for } n \geq 0
$$

$0<k=\left((1-t)^{2}-2 t(1-t) r+t^{2} s^{2}\right)^{1 / 2}<1$ for all $t$ such that $0<t<2(1+r) /$ $\left(1+2 r+s^{2}\right)$ and $r \leq s$, converges to an element of $F$.

For $\left\{a_{n}\right\}=1$, Theorem 1 reduces to:

Corollary 1: Let $T: K \rightarrow K$ be relaxed Lipschitz and Lipschitz continuous. Let $F=\{x$ in $K: T x=x\}$ be a nonempty set. Then, for $x_{0}$ in $K$, the sequence $\left\{x_{n}\right\}$ generated by an iterative algorithm

$$
x_{n+1}=(1-t) x_{n}+t T x_{n}
$$

for $0<t<2(1+r) /\left(1+2 r+s^{2}\right)$ converges to a unique fixed point of $T$.

Proof of Theorem 1: For an element $z$ in $F$, we have

$$
\begin{gathered}
\left\|x_{n+1}-z\right\|=\left\|\left(1-a_{n}\right) x_{n}+a_{n}\left[(1-t) x_{n}+t T x_{n}\right]-z\right\| \\
\leq\left(1-a_{n}\right)\left\|\left(x_{n}-z\right)\right\|+a_{n}\left\|(1-t)\left(x_{n}-z\right)+t\left(T x_{n}-T z\right)\right\| .
\end{gathered}
$$

Using the relaxed Lipschitzity and Lipschitz continuity of $T$, we find that

$$
\begin{gathered}
\left\|t\left(T x_{n}-T z\right)+(1-t)\left(x_{n}-z\right)\right\|^{2} \\
=(1-t)^{2}\left\|x_{n}-z\right\|^{2}+2 t(1-t)\left\langle T x_{n}-z, x_{n}-z\right\rangle+t^{2}\left\|T x_{n}-z\right\|^{2} \\
\leq(1-t)^{2}\left\|x_{n}-z\right\|^{2}-2 t(1-t) r\left\|x_{n}-z\right\|^{2}+t^{2} s^{2}\left\|x_{n}-z\right\|^{2}
\end{gathered}
$$




$$
=\left((1-t)^{2}-2 t(1-t) r+t^{2} s^{2}\right)\left\|x_{n}-z\right\|^{2} .
$$

It follows that

$$
\begin{aligned}
\left\|x_{n+1}-z\right\| \leq(1- & \left.a_{n}+a_{n}\left((1-t)^{2}-2 t(1-t) r+t^{2} s^{2}\right)^{1 / 2}\right)\left\|x_{n}-z\right\| \\
& =\left(1-(1-k) a_{n}\right)\left\|x_{n}-z\right\| \\
\leq & \prod_{j=0}^{n}\left(1-(1-k) a_{j}\right)\left\|x_{0}-z\right\|
\end{aligned}
$$

where $0<k=\left((1-t)^{2}-2 t(1-t) r+t^{2} s^{2}\right)^{1 / 2}<1$ for all $t$ such that $0<t<2(1+r) /$ $\left(1+2 r+s^{2}\right)$ and $r \leq s$.

Since $\sum_{j=0}^{\infty} a_{j}$ diverges and $k<1, \lim _{n \rightarrow \infty} \sum_{j=0}^{n}\left(1-(1-k) a_{j}\right)=0$ and, as a result, $\left\{x_{n}\right\}$ converges strongly to $z$. This completes the proof.

\section{References}

[1] Halpern, B., Fixed points of nonexpanding maps, Bull. Amer. Math. Soc. 73 (1967), 957-961.

[2] Reich, S., Approximating fixed points of nonexpansive maps, PanAmerican Math J. 4:2 (1994), 23-28.

[3] Verma, R.U., Iterative algorithms for approximating fixed points of strongly monotone operators, Boletin Acad. Cien. Fis. Mat. Natur. (to appear).

[4] Verma, R.U., A fixed point theorem involving Lipschitzian generalized pseudocontractions, Proc. Royal Irish Acad. (to appear).

[5] Verma, R.U., An iterative procedure for approximating fixed points of relaxed monotone operators, Numer. Functional Anal. Optimiz. 17 (1996), 1045-1051.

[6] Wittmann, R., Approximation of fixed points of nonexpansive mappings, Arch. Math. 58 (1992), 486-491. 


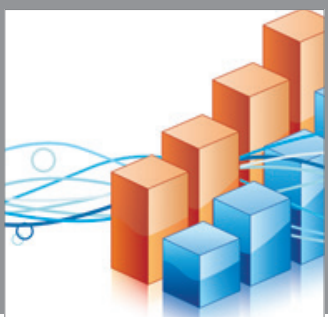

Advances in

Operations Research

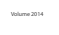

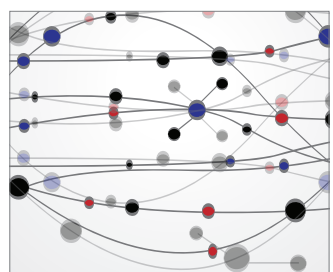

\section{The Scientific} World Journal
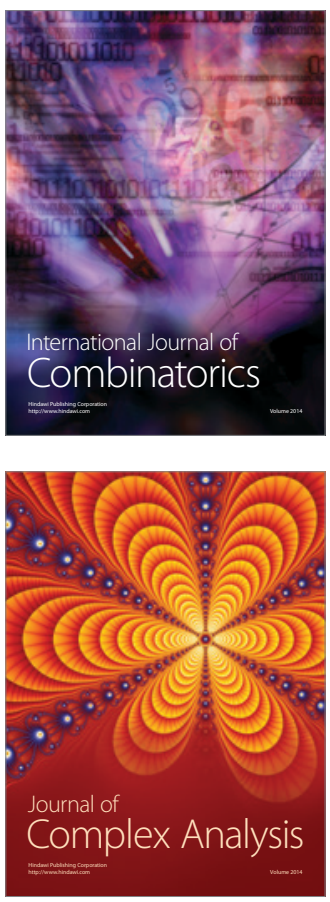

International Journal of

Mathematics and

Mathematical

Sciences
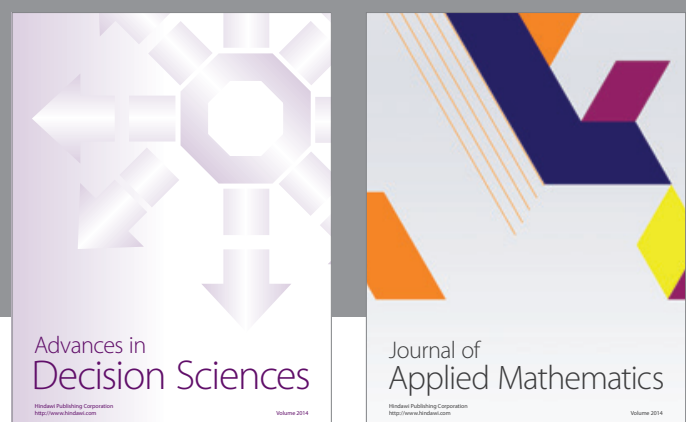

Journal of

Applied Mathematics
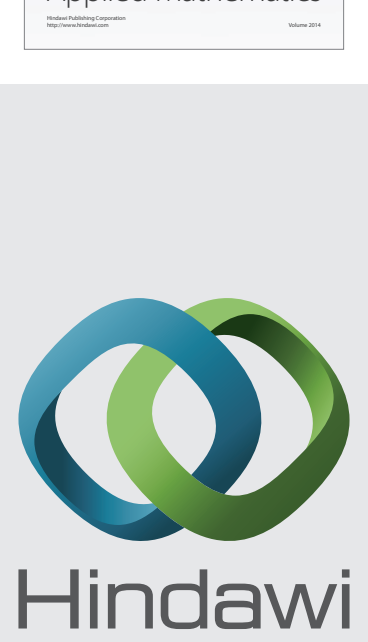

Submit your manuscripts at http://www.hindawi.com
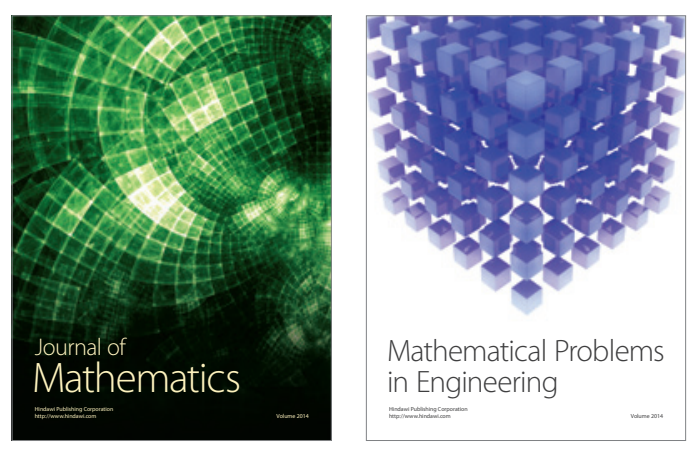

Mathematical Problems in Engineering
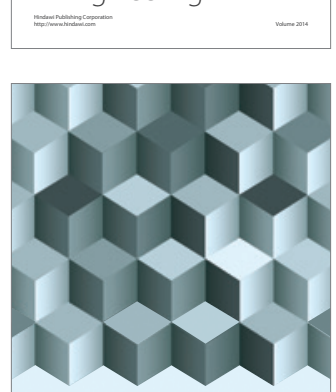

Journal of

Function Spaces
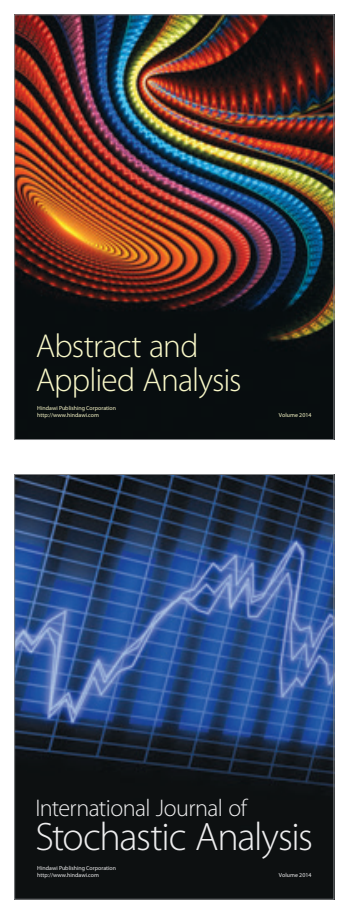

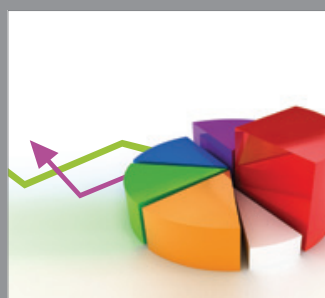

ournal of

Probability and Statistics

Promensencen
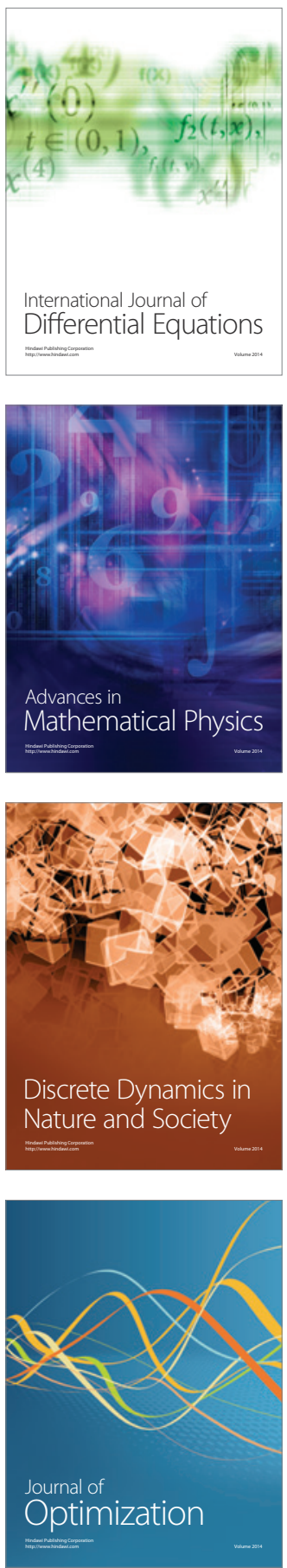